\title{
A genetic variant in the pre-miR-27a oncogene is associated with a reduced familial breast cancer risk
}

\author{
Rongxi Yang • Bettina Schlehe $\cdot$ Kari Hemminki $\cdot$ Christian Sutter \\ Peter Bugert • Barbara Wappenschmidt • Juliane Volkmann • Raymonda Varon • \\ Bernhard H. F. Weber • Dieter Niederacher · Norbert Arnold • Alfons Meindl · \\ Claus R. Bartram · Rita K. Schmutzler · Barbara Burwinkel
}

Received: 30 July 2009/Accepted: 30 October 2009/Published online: 18 November 2009

(C) Springer Science+Business Media, LLC. 2009

\begin{abstract}
MicroRNAs (miRNAs) regulate pathways involved in cell differentiation, proliferation, development, and apoptosis by degradation of target mRNAs and/or repression of their translation. Although the single nucleotide polymorphisms (SNPs) in miRNAs target sites have been studied, the effects of SNPs in miRNAs are largely unknown. In our study, we first systematically sequenced miRNA genes reported to be involved in breast cancer to identify/verify SNPs. We analyzed four SNPs, one located
\end{abstract}

R. Yang $(\bowtie) \cdot$ B. Burwinkel

Helmholtz-University Group Molecular Epidemiology,

German Cancer Research Center (DKFZ), Im Neuenheimer

Feld 581, 69120 Heidelberg, Germany

e-mail: r.yang@dkfz.de

R. Yang $\cdot$ B. Schlehe $\cdot$ B. Burwinkel

Division Molecular Biology of Breast Cancer, Department of Gynecology and Obstetrics, University of Heidelberg, 69120 Heidelberg, Germany

\section{K. Hemminki}

Division of Molecular Genetic Epidemiology, German Cancer Research Center (DKFZ), Im Neuenheimer Feld 580, 69120 Heidelberg, Germany

\section{K. Hemminki}

Department of Biosciences at Novum, Karolinska Institute,

14157 Huddinge, Sweden

C. Sutter - C. R. Bartram

Institute of Human Genetics, University of Heidelberg,

69120 Heidelberg, Germany

\section{P. Bugert}

Institute of Transfusion Medicine and Immunology, Red Cross Blood Service of Baden-Württemberg-Hessen, University of Heidelberg, Medical Faculty of Mannheim, Mannheim, Germany in the pre-miRNA and the other three located in miRNA flanking regions, for a putative association with breast cancer risk. The SNP rs895819, located in the terminal loop of pre-miRNA-27a, showed a protective effect. In a large familial breast cancer study cohort, the rare [G] allele of rs895819 was found to be less frequent in the cases than in the controls, indicating a reduced familial breast cancer risk ([G] vs. [A]: $\mathrm{OR}=0.88,95 \%$ CI $0.78-0.99, P=$ 0.0287). Furthermore, age stratification revealed that the 
protective effect was mainly observed in the age group $<50$ years of age ([G] vs. [A]: OR $=0.83,95 \% \mathrm{CI}$ $0.70-0.98, P=0.0314$ ), whereas no significant effect was observed in the age group $\geq 50$ years of age, indicating a possible hormone-related effect. It has been shown that artificial mutations in the terminal loop of miR-27a can block the maturation process of the miRNA. We hypothesize that the G-variant of rs895819 might impair the maturation of the oncogenic miR-27a and thus, is associated with familial breast cancer risk.

Keywords Breast cancer risk - MicroRNA - SNP . Case-control study

\section{Introduction}

MicroRNAs (miRNAs) are an abundant class of small endogenous noncoding RNAs (20-22 nt) that negatively regulate the target gene transcription through hybridization to incomplete complementary sequences in the $3^{\prime}$ untranslated region of their target mRNAs. It results in either the degradation of target messenger RNAs or repression of their translation [1,2]. MicroRNAs are initially transcribed from genomic DNA to long primary transcripts (pri-miRNAs) and then are cleaved by nuclear Drosha into 60-70 nt hairpin-shaped precursor RNAs (premiRNAs) [3, 4]. Pre-miRNAs are exported to the cytoplasm by Exportin-5 and are further processed into $\sim 22 \mathrm{nt}$ mature miRNA duplexes by the cleavage of Dicer [5-7]. In association with RNA-induced silencing complex (RISC), one strand of the miRNA duplex matches target mRNA sequence in the $3^{\prime}$ un-translated regions. This binding finally leads to the degradation of the mRNAs or the inhibition of their translation and consequently down-regulates the expression of the protein [8, 9]. As miRNAs can regulate multiple target mRNAs, they have been identified to be crucial in the process of immune system regulation, hematopoiesis, angiogenesis, cell development, cell proliferation, differentiation, and apoptosis [10-15]. Elevated or decreased expression of miRNAs has been found in various tumor types. Some miRNAs thereby have been considered as tumor suppressors or oncogenes [16-18]. They are shown to be involved in cancer initiation and progression by suppression and the expression of cancerrelated genes [19]. Furthermore, miRNA expression profiles can be molecular markers for cancer diagnosis and therapy [20, 21].

Breast cancer is the leading cause of cancer-related death in women and next to lung cancer, the second most common cancer in the world [22]. Up to $10 \%$ of women, who are diagnosed with breast cancer, report a family history [23, 24]. According to the polygenic model of inherited breast cancer, unfavorable combinations of polymorphic genetic variants in low-penetrance susceptibility genes contribute to the excess familial breast cancer risk. Most of these susceptibility genes have not been discovered yet $[25,26]$.

It is suggested that miRNA mutations or mis-expressions correlate with various human cancer risks [19]. Although the single nucleotide polymorphisms (SNPs) in miRNAs target sites have been studied [27-29], the effects of SNPs in miRNAs remain largely unknown. It motivated us to explore polymorphisms in the breast cancer-related miRNA genes and investigate their associations with familial breast cancer risk.

In our study, we selected 11 miRNAs from the literature (miR-373, miR-520c, miR-126, miR-335, miR-10b, let-7a-1, let-7a-2, let-7a-3, miR-27a, miR-21, and miR-145). All the 11 miRNAs have been reported to be associated with breast cancer initiation, progression, and metastasis and with known mechanisms [30-37]. We systematically scanned for SNPs located in these breast cancer-relevant miRNA genes (including pre-miRNAs and about \pm 200 bp flanking regions) by sequencing these regions, and then investigated the four most promising SNPs which were selected according to the defined criteria in a large German familial study cohort. Our analysis revealed that the [G] allele of SNP rs895819, located in pre-miR-27a oncogene, has a significant association with a reduced familial breast cancer risk.

\section{Materials and methods}

\section{Study population}

Our study cohort contains 1,217 German familial breast cancer (BC) patients and 1,422 unrelated healthy German women. The breast cancer index cases were tested $B R C A 1 / 2$ mutation-negative by applying mutational screening on all exons with denaturing high performance liquid chromatography (DHPLC), and followed by direct sequencing of conspicuous exons [38]. All the 1,217 familial breast cancer cases are $B R C A 1$ and $B R C A 2$ mutation negative. In the case group, 115 patients had bilateral breast cancer and were considered as a subgroup. The BC samples were collected during the years 1997-2007 by seven centers of the German Consortium for Hereditary Breast and Ovarian Cancer (centres of Heidelberg, Würzburg, Cologne, Kiel, Düsseldorf, Munich, and Berlin, see authors' affiliations). German index patients were first diagnosed with breast cancer and then referred to a family registry. The informed consent for the study was given to all the breast cancer patients. About $3 \%$ of patients refused to donate their blood samples for research purposes. 
The control population included unrelated healthy female blood donors collected by the German Red Cross Blood Service of Baden-Wuerttemberg-Hessia and Institute of Transfusion Medicine and Immunology (Mannheim), sharing the same ethnic background with the breast cancer patients (Caucasian/German population). All of the control population are healthy when they donated their blood, and none of them has a reported familial history of breast cancer. Age distributions in controls and breast cancer cases were similar (controls: mean age 45.8 years, median age 49 years, range from 18 to 68 years; cases: mean age 46.2 years, median age 46 years, range from 19 to 87 years). The controls were randomly selected during the years 2004-2007 for this study, and no further inclusion criteria were applied during recruitment. This study was approved by the Ethics Committee of the University of Heidelberg (Heidelberg, Germany). According to the German guidelines for blood donation, all blood donors were examined by a standard questionnaire. The informed consent for this study was given to all the participants. About 5\% of blood donors refused to use their blood samples for research purposes.

\section{SNP verification and sequencing}

Breast cancer-related 11 miRNA genes were selected from the literature. In order to verify annotated single SNPs from the SNP database (NCBI) and to identify potential new SNPs, 11 miRNA genes, including pre-miRNAs and about \pm 200 bp flanking regions, were amplified by the standard PCR (in order to unfold the secondary structure of miRNAs, 5\% DMSO was added to the PCR buffer). Owing to high homology with other genomic regions, specific primer design was not possible for miR-520c. Thus, miR-520c was not further analyzed. PCR products were purified with the ExoSAP-IT purification kit (USB Corp.) and were then sequenced in one of the directions by the 3130XL Genetic Analyzer (Applied Biosystems). Sequencing results were analyzed with Sequencing Analysis 5.2 software (Applied Biosystems). As a result, 10 SNPs were verified in these segments. Sequences of primers are available upon request.

\section{Genotyping}

According to our defined criteria, five out of 10 SNPs (rs12983273 located $127 \mathrm{bp}$ upstream of pre-miR-373, rs4636297 located 12 bp downstream of miR-126, rs7310 85 located 63 bp downstream of pre-let-7a-3, rs3807348 located 62 bp downstream of pre-miR-335, and rs895819 in the pre-miR-27a, Table 1) were selected for further investigation for their putative influence on breast cancer risk. The three SNPs, rs12883273, rs731085, and rs3807348 were analyzed by the method of TaqMan allelic discrimination. However, the TaqMan assay performance of rs4636297 in miR-126 could not be improved even when adding DMSO, formamide, or alternating the temperature profile. The SNP rs895819 could not be analyzed by TagMan assay due to failed primer and probe design. As rs895819 is the only SNP located within the pre-miRNA, which we were especially interested in, we genotyped this SNP by sequencing as describe above. Primers and TaqMan MGB probes were purchased from Applied Biosystems (Foster City, CA). Genomic DNA of $5 \mathrm{ng}$ was used for each reaction. PCR cycling conditions were as follows: $50^{\circ} \mathrm{C}$ for $2 \mathrm{~min}, 95^{\circ} \mathrm{C}$ for $10 \mathrm{~min}$, and $45-50$ cycles of $\left(92^{\circ} \mathrm{C}, 15 \mathrm{~s}\right.$, and $\left.60^{\circ} \mathrm{C}, 60 \mathrm{~s}\right)$. Samples were analyzed with SDS 1.2 software (Applied Biosystems) in ABI Prism 7900 HT detection system. The TaqMan SNP assay results were validated by regenotyping $10 \%$ of all the samples. The concordance rate was $100 \%$. Sequences of primers and probes are available upon request.

\section{Statistical analysis}

Hardy-Weinberg equilibrium test was undertaken using the chi-square "goodness-of-fit" test by a tool from the Institute of Human Genetics, Technical University Munich, Munich, Germany (http://ihg.gsf.de/cgi-bin/hw/hwa1.pl). Genotypespecific odds ratios (OR), 95\% confidence intervals (CI), and $P$ values were computed by unconditional logistic regression with SAS version 9.1 (SAS Institute Inc., Cary, NC). Age, treated as a continuous variable was included in the regression as covariate. $P$ values were calculated using two-sided chi-square test. The power $(\alpha=0.05)$ was calculated using the power and sample size calculation software PS version 2.1.31 (http://www.mc.vanderbilt.edu/prev $\mathrm{med} / \mathrm{ps} /$ index.htm) [39]. SNPs linked with all the $10 \mathrm{SNPs}$ (Table 1) with $r^{2} \geq 0.8$ and block definition were identified using HaploView version 3.32 (http://www.broad.mit.edu/ $\mathrm{mpg}$ /haploview). The linked SNPs' breast cancer associations were further verified whether they had been analyzed by the Cancer Genetic Markers of Susceptibility genome wide association study (CGEMS) (https://caintegrator.nci. nih.gov/cgems/browseSetup.do).

\section{Results}

We performed a systematic literature and database search in NCBI and found 11 miRNAs (miR-373, miR-520c, miR126, miR-335, miR-10b, let-7a-1, let-7a-2, let-7a-3, miR$27 \mathrm{a}, \mathrm{miR}-21$, miR-145) to be involved in breast cancer with known mechanisms [30-37]. In order to identify potential new SNPs as well as to verify the annotated SNPs from the 
Table 1 Searching for SNPs in breast cancer-related miRNAs in German familial breast cancer cases by sequencing

\begin{tabular}{|c|c|c|c|c|c|c|}
\hline $\mathrm{SNP}^{\mathrm{a}}$ & Genotypes & $\begin{array}{l}\text { Sequencing } \\
\text { results }(\%)^{b}\end{array}$ & $\begin{array}{l}\text { Distance to the } \\
\text { pre-miRNA (bp) }\end{array}$ & $\begin{array}{l}\text { Genotype } \\
\text { frequencies } \\
\text { in } \mathrm{NCBI}^{\mathrm{c}}\end{array}$ & CGEMS data $^{\mathrm{d}}$ & $\begin{array}{l}\text { Linkage SNPs } \\
\text { in } 200 \mathrm{~kb} \\
\text { flanking region }\end{array}$ \\
\hline rs12983273 miR-373 & $\begin{array}{l}\text { GG } \\
\text { GA } \\
\text { AA }\end{array}$ & Not sequenced & -127 & $\begin{aligned} \mathrm{GG} & =0.76 \\
\mathrm{GA} & =0.37 \\
\mathrm{AA} & =0.08\end{aligned}$ & Not investigated & $\begin{array}{c}\text { No linkage SNPs } \\
\text { with } r^{2}>0.8\end{array}$ \\
\hline rs10425222 miR-373 & $\begin{array}{l}\mathrm{CC} \\
\mathrm{AC} \\
\mathrm{AA}\end{array}$ & $\begin{array}{l}116(93.5) \\
8(6.5) \\
0(0)\end{array}$ & +172 & $\begin{array}{l}\mathrm{CC}=0.93 \\
\mathrm{AC}=0.07\end{array}$ & Not investigated & $\begin{array}{l}\text { rs } 4619513, r^{2}=1.0 \\
\text { not been investigated } \\
\text { by CGEMS }\end{array}$ \\
\hline New SNP miR-373 & $\begin{array}{l}\mathrm{CC} \\
\mathrm{CT} \\
\mathrm{TT}\end{array}$ & $\begin{array}{l}115(92.7) \\
9(7.3) \\
0(0)\end{array}$ & +114 & $\sim$ & Not investigated & $\sim$ \\
\hline rs4636297 miR-126 & $\begin{array}{l}\text { GG } \\
\text { GA } \\
\text { AA }\end{array}$ & $\begin{array}{l}50(43.9) \\
45(39.5) \\
19(16.7)\end{array}$ & +12 & $\sim$ & Not investigated & $\sim$ \\
\hline rs3807348 miR-335 & $\begin{array}{l}\text { AA } \\
\text { AG } \\
\text { GG }\end{array}$ & $\begin{array}{l}60(40.3) \\
57(38.3) \\
32(21.5)\end{array}$ & +62 & $\sim$ & Not investigated & $\sim$ \\
\hline rs41272366 miR-335 & $\begin{array}{l}\text { TT } \\
\text { TA } \\
\text { AA }\end{array}$ & $\begin{array}{l}145(97.3) \\
4(2.7) \\
0(0)\end{array}$ & +20 & $\sim$ & Not investigated & $\sim$ \\
\hline rs1867863 miR-10b & $\begin{array}{l}\text { GG } \\
\text { GT } \\
\text { TT }\end{array}$ & $\begin{array}{l}51(36.7) \\
66(47.5) \\
22(15.8)\end{array}$ & -61 & $\begin{aligned} \mathrm{GG} & =0.41 \\
\mathrm{GT} & =0.47 \\
\mathrm{TT} & =0.12\end{aligned}$ & Not investigated & $\begin{array}{l}\mathrm{rs} 4972806, r^{2}=0.89 \\
\quad P=0.31 \text { by CGEMS }\end{array}$ \\
\hline rs731085 let-7a-3 & $\begin{array}{l}\mathrm{CC} \\
\mathrm{CG} \\
\mathrm{GG}\end{array}$ & $\begin{array}{l}45(39.1) \\
53(46.1) \\
17(14.8)\end{array}$ & +63 & No Caucasian data & Not investigated & $\sim$ \\
\hline rs895819 miR-27a & $\begin{array}{l}\text { AA } \\
\text { AG } \\
\text { GG }\end{array}$ & $\begin{array}{l}53(49.5) \\
40(37.4) \\
14(13.1)\end{array}$ & In pre-miRNA-27a & $\begin{aligned} \mathrm{GG} & =0.55 \\
\mathrm{AG} & =0.37 \\
\mathrm{AA} & =0.08\end{aligned}$ & Not investigated & $\sim$ \\
\hline rs11671784 miR-27a & $\begin{array}{l}\mathrm{CC} \\
\mathrm{CT} \\
\mathrm{TT}\end{array}$ & $\begin{array}{l}102(95.3) \\
5(4.7) \\
0\end{array}$ & In pre-miRNA-27a & $\sim$ & Not investigated & $\sim$ \\
\hline miR-21 & $\sim$ & 100 & $\sim$ & $\sim$ & $\sim$ & $\sim$ \\
\hline miR-145 & $\sim$ & 117 & $\sim$ & $\sim$ & $\sim$ & $\sim$ \\
\hline let-7a-1 & $\sim$ & 144 & $\sim$ & $\sim$ & $\sim$ & $\sim$ \\
\hline let-7a-2 & $\sim$ & 97 & $\sim$ & $\sim$ & $\sim$ & $\sim$ \\
\hline
\end{tabular}

${ }^{a}$ All SNPs located in breast cancer-related miRNA or their flanking regions ( $\left.\pm 200 \mathrm{bp}\right)$. The SNPs used in further investigation shown in bold letters

b The miRNA genes (including the pre-miRNA and \pm 200 bp flanking regions) were sequenced in a sample set of more than 100 familial breast cancer cases (the number of each genotype is given and percentage is given in bracket)

c All the genotype frequencies listed here are Caucasian data from NCBI (http://www.ncbi.nlm.nih.gov/)

${ }^{\mathrm{d}}$ Data from cancer genetic markers of susceptibility genome wide association study (CGEMS) (https://caintegrator.nci.nih.gov/cgems/ browseSetup.do)

NCBI SNP database in these segments, we sequenced these 10 pre-miRNA genes in a sample set of more than 100 randomly chosen familial breast cancer cases. We found 10 SNPs in six pre-miRNAs or their flanking regions
(miR-373, miR-226, miR-335, miR-10b, let-7a-3, and miR-27a, Table 1); evaluation of miR-520c failed because of high homology with other genomic regions making specific primer design impossible. No SNPs were found in 
the other four pre-miRNAs or their flanking regions (miR21, miR-145, let-7a-1, and let-7a-2, Table 1).

In order to determine the most interesting candidates for the investigation of breast cancer risk, we analyzed $200 \mathrm{~kb}$ flanking regions of all the $10 \mathrm{SNPs}$, including the haplotype blocks of these SNPs by HaploView. We further investigated whether the SNPs themselves and their linkage SNPs $\left(r^{2} \geq 0.8\right)$ had been analyzed, so far, by the Cancer CGEMS. The CGEMS is a whole-genome association study conducted by the National Cancer Institute (NCI) enterprise to identify breast cancer susceptibility genes using Illumina HumanHap550 assays on approximately 1,200 breast cancer patients and 1,200 control subjects. If the SNPs or their linkage SNPs $\left(r^{2} \geq 0.8\right)$ have been analyzed in CGEMS and didn't show any indication for a possible association with breast cancer ( $P$ value of allele or genotype comparison between cases and controls is larger than 0.2), they were excluded from further analysis. This was the case for SNP rs1867863. Furthermore, SNPs with a rare homozygote frequency of less than $1 \%$ were also excluded due to the limited power of the study. Base on these criteria, 5 SNPs (rs12983273 located $127 \mathrm{bp}$ upstream of pre-miR-373, rs4636297 located $12 \mathrm{bp}$ downstream of miR-126, rs 731085 located 63 bp downstream of pre-let-7a-3, rs3807348 located 62 bp downstream of pre-miR-335 and rs895819 in the pre-miR-27a) were identified (Table 1).

Genotype analysis of these SNPs was performed first on genomic DNA of a subset of our study cohort, which contains BRCA1/2 mutation-negative index patients from 797 German breast cancer families with a mean age of 45.8 years, and 758 unrelated German control individuals with a mean age of 48 years. The TaqMan assay performance of rs4636297 in miR-126 failed and could not be improved even with adding DMSO, formamide or alternating the temperature profile, and thus, was not considered for further investigation. All of the samples sequenced previously were genotyped again by the TaqMan assay and attained concordance rates of $100 \%$. As rs 895819 showed a significant association with familial breast cancer, this SNP was further analyzed on an enlarged sample set (in total 1,217 familial breast cancer cases versus 1,422 controls; see materials and methods). In the investigation of rs 895819 on the whole sample set, we reached a $97.7 \%$ callrate in cases $(1,189)$ and a $99.5 \%$ callrate in controls $(1,416)$. Genotype distributions in controls and cases were consistent with the Hardy-Weinberg equilibrium (HWE). In all the SNPs analyzed, the $P$ value is larger than 0.05 . The TaqMan assay results were validated by regenotyping $10 \%$ of all the samples attaining concordance rates of more than $99.5 \%$ for all the investigated SNPs.

Genotype frequencies of rs12983273, rs731085, and rs3807348 were similar between familial breast cancer cases and control samples, showing no association with familial breast cancer (Table 2). The analysis of the polymorphism rs895819, which is the only SNP located in the pre-miRNA, revealed a significant association with familial breast cancer. The rare G-variant allele was less frequent in cases than in controls ([G] vs. $[\mathrm{A}]$ : $\mathrm{OR}=0.88,95 \% \mathrm{CI}$ $0.78-0.99, P=0.0287 ; P_{\text {trend }}=0.0288$, Table 2$)$.

The age stratification (age $<50$ years and $\geq 50$ years) showed that the protective effect of the [G] allele of rs895819 was mainly in the younger age group $(<50$ years of age) with slightly more decreased risk ([G] vs. [A]: $\mathrm{OR}=0.83,95 \% \quad$ CI $0.70-0.98, P=0.0314 ; \quad P_{\text {trend }}=$ 0.0336 , Table 3$)$. In contrast, in the older age group ( $\geq 50$ years of age), the genotype frequencies of rs895819 showed no significant association with familial breast cancer (Table 3). In the subgroup of bilateral familial breast cancer cases, the protective effect was even slightly stronger ( $[\mathrm{G}]$ vs. $[\mathrm{A}]: \mathrm{OR}=0.70,95 \%$ CI $0.52-0.95$, $P=0.0238 ; P_{\text {trend }}=0.0215$, Table 3 ).

\section{Discussion}

In recent studies, increasing evidences suggest that miRNAs are crucial factors in cancer progress as oncogenes or tumor suppressors by degradation of the target mRNAs and/or inhibition of their translation [40]. MicroRNAs are also considered to be potential biomarkers and therapeutic targets in human cancers [41]. Variations in expression of miRNAs have been reported to be related to many tumors including breast cancer [20,21], and miRNAs are also involved in breast cancer progress [42]. Differential miRNA expression could be caused by sequence variations, such as mutations and SNPs. So far, SNPs in the miRNA target sites have been widely studied [27-29], but the association between SNPs in miRNAs and familial breast cancer risk remains still largely unknown.

Our study is focused on the SNPs in the breast cancerrelated miRNAs. In addition to affecting the target hybridization [27], a mutation or a SNP in a miRNA gene may also have an impact on the transcription and/or procession of the pri- and pre-miRNAs [43]. Thus, we took the pre-miRNAs and their flanking regions (about $\pm 200 \mathrm{bp}$ ) into consideration. Furthermore, as the mutations in BRCA1 and BRCA2 account for approximately $30 \%$ of familial breast cancer cases in Germany [38], only BRCA1/2 mutation-negative familial breast cancer cases were included in our study to rule out the influence of the disease-associated mutations. Given our sample size, we obtained a power of $80 \%(\alpha=0.05)$ to detect an OR of 0.80 for SNP rs895819, not considering the usage of familial cases. The power of an association study based on familial cases was even about two times higher than that of unselected cases [44, 45]. 
Table 2 Genotype frequencies of SNPs in selected miRNAs in German study population

\begin{tabular}{|c|c|c|c|c|c|c|}
\hline SNP & Genotypes & Case $(\%)$ & Control (\%) & OR & $95 \% \mathrm{CI}$ & $P$ \\
\hline \multirow[t]{5}{*}{ miR-373 rs12983273 } & $\mathrm{CC}$ & $566(73.7)$ & $540(73.3)$ & 1.000 & & \\
\hline & $\mathrm{CT}$ & $184(24.0)$ & $175(23.7)$ & 1.008 & $0.794-1.280$ & 0.9477 \\
\hline & $\mathrm{TT}$ & $18(2.3)$ & $22(3.0)$ & 0.854 & $0.451-1.619$ & 0.6295 \\
\hline & {$[\mathrm{T}]$ vs. $[\mathrm{C}]$} & & & 0.947 & $0.795-1.193$ & 0.7969 \\
\hline & & & & & & $P_{\text {trend }}=0.8009^{\mathrm{a}}$ \\
\hline \multirow[t]{5}{*}{ miR-335 rs3807348 } & AA & 257 (32.9) & $234(31.8)$ & 1.000 & & \\
\hline & $\mathrm{AG}$ & $373(47.8)$ & $368(50.0)$ & 0.917 & $0.729-1.153$ & 0.4564 \\
\hline & GG & $150(19.2)$ & $134(18.2)$ & 1.015 & $0.756-1.361$ & 0.9224 \\
\hline & {$[\mathrm{G}]$ vs. $[\mathrm{A}]$} & & & 0.994 & $0.860-1.149$ & 0.9372 \\
\hline & & & & & & $P_{\text {trend }}=0.9374^{\mathrm{a}}$ \\
\hline \multirow[t]{5}{*}{ let $7 a-3$ rs731085 } & GG & $306(39.2)$ & $308(42.2)$ & 1.000 & & \\
\hline & GC & $365(46.7)$ & $324(44.4)$ & 1.125 & $0.904-1.400$ & 0.2911 \\
\hline & $\mathrm{CC}$ & $110(14.1)$ & $97(13.3)$ & 1.152 & $0.839-1.583$ & 0.3827 \\
\hline & {$[\mathrm{C}]$ vs. $[\mathrm{G}]$} & & & 1.087 & $0.936-1.261$ & 0.2741 \\
\hline & & & & & & $P_{\text {trend }}=0.2780^{\mathrm{a}}$ \\
\hline \multirow[t]{5}{*}{ miR-27a rs895919 } & AA & $576(48.4)$ & $605(42.7)$ & 1.000 & & \\
\hline & $\mathrm{AG}$ & $486(40.9)$ & $660(46.6)$ & 0.774 & $0.657-0.911$ & 0.0021 \\
\hline & GG & $127(10.7)$ & $151(10.7)$ & 0.883 & $0.680-1.148$ & 0.3543 \\
\hline & {$[\mathrm{G}]$ vs. $[\mathrm{A}]$} & & & 0.878 & $0.781-0.987$ & 0.0287 \\
\hline & & & & & & $P_{\text {trend }}=0.0288^{\mathrm{a}}$ \\
\hline
\end{tabular}

Adjusted for age; all analyses done with SAS Version 9.1 Proc Logistic

a Chi-square test for trend

Table 3 Genotype frequencies of rs895819 within pre-miRNA-27a in familial breast cancer subgroups

\begin{tabular}{|c|c|c|c|c|c|c|}
\hline SNP & Genotypes & Case $(\%)$ & Control $(\%)$ & OR & $95 \% \mathrm{CI}$ & $P$ \\
\hline \multirow[t]{5}{*}{ miR-27a rs895919 age $\geq 50$} & AA & $173(45.4)$ & $302(43.5)$ & 1.000 & & \\
\hline & $\mathrm{AG}$ & $167(43.8)$ & $319(46.0)$ & 0.915 & $0.701-1.193$ & 0.5106 \\
\hline & GG & $41(10.8)$ & $73(10.5)$ & 0.984 & $0.642-1.507$ & 0.9397 \\
\hline & {$[\mathrm{G}]$ vs. $[\mathrm{A}]$} & & & 0.965 & $0.799-1.165$ & 0.7099 \\
\hline & & & & & & $P_{\text {trend }}=0.7072^{\mathrm{a}}$ \\
\hline \multirow[t]{5}{*}{ miR-27a rs895919 age $<50$} & AA & $403(49.9)$ & $303(42.0)$ & 1.000 & & \\
\hline & AG & $319(39.5)$ & $341(47.2)$ & 0.735 & $0.579-0.932$ & 0.0109 \\
\hline & GG & $86(10.6)$ & $78(10.8)$ & 0.785 & $0.536-1.149$ & 0.2132 \\
\hline & {$[\mathrm{G}]$ vs. $[\mathrm{A}]$} & & & 0.830 & $0.701-0.984$ & 0.0314 \\
\hline & & & & & & $P_{\text {trend }}=0.0336^{\mathrm{a}}$ \\
\hline \multirow[t]{5}{*}{ miR-27a rs895919 bilateral } & AA & $61(54.0)$ & $605(42.7)$ & 1.000 & & \\
\hline & $\mathrm{AG}$ & $44(38.9)$ & $660(46.6)$ & 0.662 & $0.442-0.991$ & 0.0448 \\
\hline & GG & $8(7.1)$ & $151(10.7)$ & 0.525 & $0.246-1.121$ & 0.0961 \\
\hline & {$[\mathrm{G}]$ vs. $[\mathrm{A}]$} & & & 0.703 & $0.518-0.954$ & 0.0238 \\
\hline & & & & & & $P_{\text {trend }}=0.0215^{\mathrm{a}}$ \\
\hline
\end{tabular}

Adjusted for age; all analyses done with SAS Version 9.1 Proc Logistic

${ }^{\text {a }}$ Chi-square test for trend

The three SNPs located in the pre-miRNA flanking regions (rs12983273 located 127 bp upstream of pre-miR373 , rs 731085 located 63 bp downstream of pre-let-7a-3, rs3807348 located $62 \mathrm{bp}$ downstream of pre-miR-335, rs895819 in the pre-miR-27a, Table 1), did not show a significant association with familial breast cancer. 
However, the [G] allele of rs895819 in the pre-miR-27a oncogene was associated with a decreased breast cancer risk. This effect was even stronger in the subgroup of $<50$ years of age and in bilateral familial breast cancer cases with slightly decreased respective ORs, whereas no significant effect was observed in the $\geq 50$ years of age group. The potential age- or hormone-related effect is discussed later in this section. In bilateral breast cancer cases (a second primary tumor in the contralateral breast), it is believed that the underlying "mutation" is not limited to the epithelial cells of one breast but rather systemic variation [46]. Bilateral breast cancer is considered to have a strong genetic background [47]. Thus, the SNP effect is expected to be stronger in this subgroup. However, due to the limited samples size of bilateral cases, it is also possible that the association of rs895819 with reduced bilateral breast cancer risk was detected by chance.

The SNP rs895819 is located in the loop of pre-miR27a. In order to investigate whether this variation might alter the secondary structure of the pre-miR-27a, we used the RNAfold program [48] (http://www.bioinfo.rpi.edu/ applications/hybrid/) to predict the most stable secondary structure of both wild-type and variant. According to the prediction of the RNAfold program, the $[\mathrm{G}]$ variant of rs895819 affected neither the pre-miR-27a's conformation nor the free energy (data not shown). It has been suggested that a mutation causing structural change in the crucial region of miRNA could affect the maturation and the process of miRNA [49-51]. Furthermore, Wu et al. found that even some SNPs with no influence on miRNA secondary structure can affect the expression of miRNA through some unclear mechanism, suggesting that the processing and maturation of miRNA is more complex and subtle than predicted [43]. Zeng et al. suggested that Drosha selectively cleaves RNA hairpins bearing a large terminal loop. When the loop is shortened by mutation or deletions, the maturation process will be harmed [52]. In their study, an A-G mutation was introduced to the terminal loop of miR-27a. As a result, reduced productions of both pre-miRNA-27a and mature miRNA-27a were observed when the size of the terminal loop was reduced by the new bonds formed by mutations [52]. According to the predicted structure of miR-27a, rs895819 is located in the center of the terminal loop. The $[\mathrm{A}]-[\mathrm{G}]$ variant of rs895819 may result in an additional $\mathrm{C}-\mathrm{G}$ binding with a [C] allele in the loop, which will probably reduce the size of the loop. Consequently the cleavage by Drosha would be blocked, and the maturation process is thereby inhibited. Piskounova et al. showed that some Drosha inhibitors such as Lin28, selectively bind to the terminal loop region of miRNA precursors and mediate the miRNA procession $[53,54]$. Thus, it is also possible that the $[\mathrm{A}]-[\mathrm{G}]$ variant changes the binding affinity of some Drosha inhibitors and consequently affects the processing of miR-27a. In conclusion, we hypothesize that rs895819 may play an important role in the maturation of miR-27a. However, this hypothesis needs to be tested.

By means of the mRNA target gene prediction database (http://microrna.sanger.ac.uk/), we found more than 1,000 target genes of miR-27a, including some cancer-related genes, such as aspartate-specific cysteine protease (CASP8) [55], mutL homolog 1(MLH1), vascular endothelial growth factor $\mathrm{C}(V E G F C)$, and BCL2-associated X protein $(B A X)$. Scott et al. found that the transcription of ZBTB10 is upregulated after miR-27a antisense transfection [56]. In consistence with this result, Mertens-Talcott et al. [36] suggested that transfection of antisense miR-27a results in increased expression of ZBTB10 mRNA (a SP1 suppressor) and consequently decreases the expression of specificity proteins, SP1, SP3 and SP4, which are overexpressed in tumors and contribute to the proliferative and angiogenic phenotype of cancer cells. Moreover, the transfection of antisense miR-27a was also accompanied by decreased expression of Sp-dependent survival and angiogenic genes, such as survivin, vascular endothelial growth factor (VEGF), and VEGF receptor 1 (VEGFRl) [36]. MertensTalcott et al. [36] also found the transfection of antisense miR-27a increases Myt-1 mRNA levels and enhances phosphorylation of cdc2. Thus, the percentage of cells in $\mathrm{G}_{2}-\mathrm{M}$ was consequently increased. Other studies also found that the suppression of miR-27a can inhibit gastric cancer cell growth [57] and overexpression of miR-27a increases the fat accumulation and cell proliferation of Hepatic stellate cells [58]. Therefore, miR-27a is considered as an oncogene. Our results consistently, showed that the wild genotype [AA] had higher frequency in cases than in controls, whereas the variant [G] allele reduced the risk of miR-27a. We propose that the [G] allele of rs895819 attenuates the maturation process of oncogenic miR-27a.

Several reports demonstrated that SP1 and other Sp proteins play an important role in regulation of $17 \beta$-estradiol $\left(\mathrm{E}_{2}\right)$-dependent genes in breast cancer cell lines and in many other cell-types $[59,60]$. The $17 \beta$-estradiol $\left(\mathrm{E}_{2}\right)$ dependent interaction of estrogen receptor (ER) and $\mathrm{Sp}$ proteins modulates the activation of a cluster of genes [61, 62], for example, $c$-fos, IGF-binding protein 4 (IGFBP-4), B-cell lymphoma 2 (Bcl2), E2F transcription factor 1 $(E 2 F 1)$, vascular endothelial growth factor $(V E G F)$ and cyclin D1 [63]. A recent study reported that Sp proteins are involved in the estrogen-induced transcription of $B R C A 1$ [64]. As the expression of Sp proteins is regulated by miR27a [36], it may explain why the protective impact of the rs895819 variant in pre-miR-27a was predominantly observed in premenopausal woman.

Furthermore, the expression of $P$-glycoprotein and MDR1 mRNA is decreased by the treatment of multidrug 
resistant (MDR) cancer cell lines with the antago-miRs of miR-27a, which is accompanied by enhanced intracellular accumulation of cytotoxic drugs that are transported by $P$-glycoprotein [65]. It suggests that the rs895819 variant might influence the therapeutic outcome. A report from Japan found the frequency of $[\mathrm{G}]$ allele of rs895819 to be increased in males with peptic ulcer or severe mucosal atrophy compared to control individuals [66], which is the opposite direction we have observed in our study. The study showed no significant association in the whole study population and female subgroup, whereas a borderline significant was found in the male subgroup [66].As their investigated sample set was small (23 male controls and 91 male cases), their detected genotype frequency might not be representative. On the contrary, their result suggested a difference between male and female and indicated the possible gender specific effect of rs895819. It is the same as we hypothesized that miR-27a might be involved in the estrogen dependent pathway.

Our study systematically focused on SNPs located in breast cancer-related miRNAs. Recent studies have found more miRNAs involved in progression of breast cancer [67, 68]. Under strong selections, hundreds of miRNA genes have been found in various species, and many miRNA genes are highly conserved [2]. Thus, SNPs, especially SNPs with allele frequency larger than 5\% are underrepresented in miRNAs. Because of the limited sample size of our study, we only investigated SNPs with an allele frequency $>5 \%$. As the miRNAs have important biological functions, it would be of great relevance to investigate the SNPs in the miRNAs. Although some of the very rare mutations or SNPs are more likely to be already deleterious in earlier disease, it would be also interesting to investigate all SNPs and mutations within miRNAs, especially the ones in the miRNA 'seed' regions, for a putative effect on cancer risk. Owing to the rare frequency of these variants within miRNAs, very large study populations are required, which can only be achieved in multicenter collaborations.

In summary, we found that the [G] allele of rs895819, located in the terminal loop of in pre-miR-27a oncogene, is associated with reduced familial breast cancer risk. However, large studies from multicenter studies will be necessary to verify the association.

Acknowledgments We thank Ludwig Heesen, Michelle Dick, Ying Wang, and Anja Schwaeger for their help in genotyping. We are grateful to Bowang Chen for statistical analysis as well as to Sandrine Tchatchou for the technical support. The German breast cancer samples were collected as a part of a project funded by the Deutsche Krebshilfe (Grant number: 107054). This study was supported by the Helmholtz society, the German Cancer Research Center (DKFZ), EU, LSHC-CT-2004-503465, and the Dietmar-Hopp Foundation.

\section{References}

1. Bartel DP (2004) MicroRNAs: genomics, biogenesis, mechanism, and function. Cell 116:281-297

2. Ambros V (2004) The functions of animal microRNAs. Nature 431:350-355

3. Lee Y, Jeon K, Lee JT, Kim S, Kim VN (2002) MicroRNA maturation: stepwise processing and subcellular localization. EMBO J 21:4663-4670

4. Lee Y, Ahn C, Han J, Choi H, Kim J, Yim J, Lee J, Provost P, Radmark O, Kim S et al (2003) The nuclear RNase III Drosha initiates microRNA processing. Nature 425:415-419

5. Lund E, Guttinger S, Calado A, Dahlberg JE, Kutay U (2004) Nuclear export of microRNA precursors. Science 303:95-98

6. Hutvagner G, McLachlan J, Pasquinelli AE, Balint E, Tuschl T, Zamore PD (2001) A cellular function for the RNA-interference enzyme Dicer in the maturation of the let-7 small temporal RNA. Science 293:834-838

7. Ketting RF, Fischer SE, Bernstein E, Sijen T, Hannon GJ, Plasterk RH (2001) Dicer functions in RNA interference and in synthesis of small RNA involved in developmental timing in $C$. elegans. Genes Dev 15:2654-2659

8. Martinez J, Patkaniowska A, Urlaub H, Luhrmann R, Tuschl T (2002) Single-stranded antisense siRNAs guide target RNA cleavage in RNAi. Cell 110:563-574

9. Schwarz DS, Hutvagner G, Haley B, Zamore PD (2002) Evidence that siRNAs function as guides, not primers, in the Drosophila and human RNAi pathways. Mol Cell 10:537-548

10. Baltimore D, Boldin MP, O'Connell RM, Rao DS, Taganov KD (2008) MicroRNAs: new regulators of immune cell development and function. Nat Immunol 9:839-845

11. Brennecke J, Hipfner DR, Stark A, Russell RB, Cohen SM (2003) Bantam encodes a developmentally regulated microRNA that controls cell proliferation and regulates the proapoptotic gene hid in Drosophila. Cell 113:25-36

12. Chang TC, Wentzel EA, Kent OA, Ramachandran K, Mullendore M, Lee KH, Feldmann G, Yamakuchi M, Ferlito M, Lowenstein CJ et al (2007) Transactivation of miR-34a by p53 broadly influences gene expression and promotes apoptosis. Mol Cell 26:745-752

13. Calin GA, Cimmino A, Fabbri M, Ferracin M, Wojcik SE, Shimizu M, Taccioli C, Zanesi N, Garzon R, Aqeilan RI et al (2008) MiR-15a and miR-16-1 cluster functions in human leukemia. Proc Natl Acad Sci USA 105:5166-5171

14. Dews M, Homayouni A, Yu D, Murphy D, Sevignani C, Wentzel E, Furth EE, Lee WM, Enders GH, Mendell JT et al (2006) Augmentation of tumor angiogenesis by a Myc-activated microRNA cluster. Nat Genet 38:1060-1065

15. Xiao C, Rajewsky K (2009) MicroRNA control in the immune system: basic principles. Cell 136:26-36

16. Johnson SM, Grosshans H, Shingara J, Byrom M, Jarvis R, Cheng A, Labourier E, Reinert KL, Brown D, Slack FJ (2005) RAS is regulated by the let-7 microRNA family. Cell 120:635647

17. He L, Thomson JM, Hemann MT, Hernando-Monge E, Mu D, Goodson S, Powers S, Cordon-Cardo C, Lowe SW, Hannon GJ et al (2005) A microRNA polycistron as a potential human oncogene. Nature 435:828-833

18. O'Donnell KA, Wentzel EA, Zeller KI, Dang CV, Mendell JT (2005) c-Myc-regulated microRNAs modulate E2F1 expression. Nature 435:839-843

19. Esquela-Kerscher A, Slack FJ (2006) Oncomirs-microRNAs with a role in cancer. Nat Rev Cancer 6:259-269

20. Calin GA, Croce CM (2006) MicroRNA signatures in human cancers. Nat Rev Cancer 6:857-866 
21. Lu J, Getz G, Miska EA, Alvarez-Saavedra E, Lamb J, Peck D, Sweet-Cordero A, Ebert BL, Mak RH, Ferrando AA et al (2005) MicroRNA expression profiles classify human cancers. Nature 435:834-838

22. Parkin DM, Bray F, Ferlay J, Pisani P (2005) Global cancer statistics, 2002. CA Cancer J Clin 55:74-108

23. Hopper JL (2001) Genetic epidemiology of female breast cancer. Semin Cancer Biol 11:367-374

24. Narod SA (2002) Modifiers of risk of hereditary breast and ovarian cancer. Nat Rev Cancer 2:113-123

25. Ponder BA (2001) Cancer genetics. Nature 411:336-341

26. Pharoah PD, Antoniou A, Bobrow M, Zimmern RL, Easton DF, Ponder BA (2002) Polygenic susceptibility to breast cancer and implications for prevention. Nat Genet 31:33-36

27. Tchatchou S, Jung A, Hemminki K, Sutter C, Wappenschmidt B, Bugert P, Weber BH, Niederacher D, Arnold N, Varon-Mateeva $\mathrm{R}$ et al (2009) A variant affecting a putative miRNA target site in estrogen receptor (ESR) 1 is associated with breast cancer risk in premenopausal women. Carcinogenesis 30:59-64

28. Landi D, Gemignani F, Naccarati A, Pardini B, Vodicka P, Vodickova L, Novotny J, Forsti A, Hemminki K, Canzian F et al (2008) Polymorphisms within micro-RNA-binding sites and risk of sporadic colorectal cancer. Carcinogenesis 29:579-584

29. Kapeller J, Houghton LA, Monnikes H, Walstab J, Moller D, Bonisch H, Burwinkel B, Autschbach F, Funke B, Lasitschka F et al (2008) First evidence for an association of a functional variant in the microRNA-510 target site of the serotonin receptortype $3 \mathrm{E}$ gene with diarrhea predominant irritable bowel syndrome. Hum Mol Genet 17:2967-2977

30. Tavazoie SF, Alarcon C, Oskarsson T, Padua D, Wang Q, Bos PD, Gerald WL, Massague J (2008) Endogenous human microRNAs that suppress breast cancer metastasis. Nature 451:147-152

31. Ma L, Teruya-Feldstein J, Weinberg RA (2007) Tumour invasion and metastasis initiated by microRNA-10b in breast cancer. Nature 449:682-688

32. Yu F, Yao H, Zhu P, Zhang X, Pan Q, Gong C, Huang Y, Hu X, Su F, Lieberman J et al (2007) let-7 regulates self renewal and tumorigenicity of breast cancer cells. Cell 131:1109-1123

33. Huang Q, Gumireddy K, Schrier M, le Sage C, Nagel R, Nair S, Egan DA, Li A, Huang G, Klein-Szanto AJ et al (2008) The microRNAs miR-373 and miR-520c promote tumour invasion and metastasis. Nat Cell Biol 10:202-210

34. Lu L, Katsaros D, de la Longrais IA, Sochirca O, Yu H (2007) Hypermethylation of let-7a-3 in epithelial ovarian cancer is associated with low insulin-like growth factor-II expression and favorable prognosis. Cancer Res 67:10117-10122

35. Sempere LF, Christensen M, Silahtaroglu A, Bak M, Heath CV, Schwartz G, Wells W, Kauppinen S, Cole CN (2007) Altered microRNA expression confined to specific epithelial cell subpopulations in breast cancer. Cancer Res 67:11612-11620

36. Mertens-Talcott SU, Chintharlapalli S, Li X, Safe S (2007) The oncogenic microRNA-27a targets genes that regulate specificity protein transcription factors and the G2-M checkpoint in MDAMB-231 breast cancer cells. Cancer Res 67:11001-11011

37. Frankel LB, Christoffersen NR, Jacobsen A, Lindow M, Krogh A, Lund AH (2008) Programmed cell death 4 (PDCD4) is an important functional target of the microRNA miR-21 in breast cancer cells. J Biol Chem 283:1026-1033

38. Meindl A (2002) Comprehensive analysis of 989 patients with breast or ovarian cancer provides BRCA1 and BRCA2 mutation profiles and frequencies for the German population. Int J Cancer 97:472-480

39. Dupont WD, Plummer WD Jr (1998) Power and sample size calculations for studies involving linear regression. Control Clin Trials 19:589-601
40. Zhang B, Pan X, Cobb GP, Anderson TA (2007) MicroRNAs as oncogenes and tumor suppressors. Dev Biol 302:1-12

41. Osaki M, Takeshita F, Ochiya T (2008) MicroRNAs as biomarkers and therapeutic drugs in human cancer. Biomarkers 13:658-670

42. Verghese ET, Hanby AM, Speirs V, Hughes TA (2008) Small is beautiful: microRNAs and breast cancer-where are we now? J Pathol 215:214-221

43. Wu M, Jolicoeur N, Li Z, Zhang L, Fortin Y, L'Abbe D, Yu Z, Shen SH (2008) Genetic variations of microRNAs in human cancer and their effects on the expression of miRNAs. Carcinogenesis 29:1710-1716

44. Houlston RS, Peto J (2003) The future of association studies of common cancers. Hum Genet 112:434-435

45. Antoniou AC, Easton DF (2003) Polygenic inheritance of breast cancer: implications for design of association studies. Genet Epidemiol 25:190-202

46. Weitzel JN, Robson M, Pasini B, Manoukian S, Stoppa-Lyonnet D, Lynch HT, McLennan J, Foulkes WD, Wagner T, Tung N et al (2005) A comparison of bilateral breast cancers in BRCA carriers. Cancer Epidemiol Biomark Prev 14:1534-1538

47. Greene MH (1997) Genetics of breast cancer. Mayo Clin Proc 72:54-65

48. Markham NR, Zuker M (2005) DINAMelt web server for nucleic acid melting prediction. Nucleic Acids Res 33:W577-W581

49. Jazdzewski K, Murray EL, Franssila K, Jarzab B, Schoenberg DR, de la Chapelle A (2008) Common SNP in pre-miR-146a decreases mature miR expression and predisposes to papillary thyroid carcinoma. Proc Natl Acad Sci USA 105:7269-7274

50. Hu Z, Chen J, Tian T, Zhou X, Gu H, Xu L, Zeng Y, Miao R, Jin $\mathrm{G}, \mathrm{Ma} \mathrm{H}$ et al (2008) Genetic variants of miRNA sequences and non-small cell lung cancer survival. J Clin Investig 118:2600 2608

51. Duan R, Pak C, Jin P (2007) Single nucleotide polymorphism associated with mature miR-125a alters the processing of primiRNA. Hum Mol Genet 16:1124-1131

52. Zeng Y, Yi R, Cullen BR (2005) Recognition and cleavage of primary microRNA precursors by the nuclear processing enzyme Drosha. EMBO J 24:138-148

53. Piskounova E, Viswanathan SR, Janas M, LaPierre RJ, Daley GQ, Sliz P, Gregory RI (2008) Determinants of microRNA processing inhibition by the developmentally regulated RNAbinding protein Lin28. J Biol Chem 283:21310-21314

54. Newman MA, Thomson JM, Hammond SM (2008) Lin-28 interaction with the Let-7 precursor loop mediates regulated microRNA processing. RNA 14:1539-1549

55. Sun T, Gao Y, Tan W, Ma S, Shi Y, Yao J, Guo Y, Yang M, Zhang X, Zhang Q et al (2007) A six-nucleotide insertion-deletion polymorphism in the CASP8 promoter is associated with susceptibility to multiple cancers. Nat Genet 39:605-613

56. Scott GK, Mattie MD, Berger CE, Benz SC, Benz CC (2006) Rapid alteration of microRNA levels by histone deacetylase inhibition. Cancer Res 66:1277-1281

57. Liu T, Tang H, Lang Y, Liu M, Li X (2009) MicroRNA-27a functions as an oncogene in gastric adenocarcinoma by targeting prohibitin. Cancer Lett 273:233-242

58. Ji J, Zhang J, Huang G, Qian J, Wang X, Mei S (2009) Overexpressed microRNA-27a and 27b influence fat accumulation and cell proliferation during rat hepatic stellate cell activation. FEBS Lett 583:759-766

59. Safe S, Abdelrahim M (2005) Sp transcription factor family and its role in cancer. Eur J Cancer 41:2438-2448

60. Safe S, Kim K (2004) Nuclear receptor-mediated transactivation through interaction with Sp proteins. Prog Nucleic Acid Res Mol Biol 77:1-36 
61. Stoner M, Wormke M, Saville B, Samudio I, Qin C, Abdelrahim M, Safe S (2004) Estrogen regulation of vascular endothelial growth factor gene expression in ZR-75 breast cancer cells through interaction of estrogen receptor alpha and SP proteins. Oncogene 23:1052-1063

62. Porter W, Saville B, Hoivik D, Safe S (1997) Functional synergy between the transcription factor Sp1 and the estrogen receptor. Mol Endocrinol 11:1569-1580

63. Safe S, Kim K (2008) Non-classical genomic estrogen receptor (ER)/specificity protein and ER/activating protein-1 signaling pathways. J Mol Endocrinol 41:263-275

64. Hockings JK, Degner SC, Morgan SS, Kemp MQ, Romagnolo DF (2008) Involvement of a specificity proteins-binding element in regulation of basal and estrogen-induced transcription activity of the BRCA1 gene. Breast Cancer Res 10:R29
65. Zhu H, Wu H, Liu X, Evans BR, Medina DJ, Liu CG, Yang JM (2008) Role of microRNA miR-27a and miR-451 in the regulation of MDR1/P-glycoprotein expression in human cancer cells. Biochem Pharmacol 76:582-588

66. Arisawa T, Tahara T, Shibata T, Nagasaka M, Nakamura M, Kamiya Y, Fujita H, Hasegawa S, Takagi T, Wang FY et al (2007) A polymorphism of microRNA 27a genome region is associated with the development of gastric mucosal atrophy in Japanese male subjects. Dig Dis Sci 52:1691-1697

67. Wu H, Zhu S, Mo YY (2009) Suppression of cell growth and invasion by miR-205 in breast cancer. Cell Res 19:439-448

68. Shen J, Ambrosone CB, Zhao H (2009) Novel genetic variants in microRNA genes and familial breast cancer. Int $\mathrm{J}$ Cancer 124:1178-1182 